\title{
Editorial
}

\section{EL PAPEL DE LA ECONOMÍA EN LA PROTECCIÓN DE LOS DERECHOS HUMANOS Y DEL PLANETA}

Según Zuleta, E. (1990), el sistema político Colombiano preserva los rasgos de la democracia clásica: elecciones populares de presidente y representantes al Congreso de la República, las gobernaciones, las alcaldías y los consejos municipales; existe separación de los tres poderes públicos (ejecutivo, legislativo y judicial), y hay libertad de expresión, organización, prensa, huelga y cátedra. En este contexto, se esperaba que la descentralización administrativa, establecida en la Constitución de 1991, abriera caminos para los colombianos en la toma de decisiones y acciones para su desarrollo. No obstante, y opuesto a estos principios, el actual contexto social y político de Colombia muestra una población que, dentro del modo de producción capitalista, vive la negación de sus derechos. Este paradigma de modo de vida, se sustenta en una ideología, que desde los principios del libre mercado y la globalización, ha beneficiado a unos pocos y no ha podido resolver de manera sostenible los problemas críticos actuales de toda la sociedad, el bien común y el ambiente.

Vivimos en una sociedad donde se niegan los sujetos $y$, por lo tanto, no se respetan los derechos humanos. Actualmente, se siguen desplazando, asesinando y vulnerando a cientos de líderes políticos, sindicalistas, periodistas, campesinos, indígenas, afros, profesores, estudiantes, artistas, escritores, intelectuales, pobres e indigentes. De otro lado, según Medina, C. (2009), también persiste un conflicto

interno que se ha extendido desde la colonización española, hasta nuestros días, cuyas características actuales son: tanto la corrupción y la parapolítica, como la participación violenta de diferentes guerrillas, narcotraficantes, sicarios y bandas emergentes de paramilitares, lo cual solo ha generado desigualdades e injusticias para gran parte de la población colombiana.

Karl Marx, en el Capital, al final de su análisis sobre la plusvalía relativa, afirma que: "la producción capitalista solo sabe desarrollar la técnica y la combinación del proceso social de producción socavando, al mismo tiempo, las dos fuentes originales de toda riqueza: la tierra y el trabajador". De este texto se puede deducir sencillamente que: injusticia es producir riqueza. Así, la sociedad capitalista genera injusticia cuando no administra de manera sustentable y sostenible, las fuentes de producción de riqueza. En este punto cabe señalar que trabajador no se refiere a la clase trabajadora, únicamente, sino al ser humano en cuanto trabajador. De igual forma, tierra no se refiere a un espacio geográfico, exclusivamente, sino a un espacio donde conviven gran variedad de seres vivos y de recursos naturales y energéticos, que son finitos y hay que preservar. Entonces, se deduce, que justicia es: producir la riqueza, preservando sus dos fuentes originales: la naturaleza y el ser humano trabajador.

En esta medida, cobra vigencia el debate sobre el bien común, el cual trasciende las esferas de lo público y lo privado, ya que este, es el punto de encuentro entre estos dos. En términos de Hinkelammert, F. (2005), el bien común es un interés de todos y, por lo tanto, de cada uno. Por su parte, Chomsky, N. (1999) dice que luchar hoy por la justicia, es luchar por este bien común. Siendo así, la solución no es restringir la libertad, sino las tiranías particulares. Por tanto, la justicia no se restringe a la llamada justicia distributiva, sino que abarca toda vida humana y la vida en el planeta. 
En este contexto, en la actual etapa del capitalismo, el papel de la economía frente a los derechos humanos, en la construcción de una identidad ciudadana, es garantizar las circunstancias que hacen posible la vida humana en condiciones de dignidad. Estas condiciones son corporales e, incluso espirituales, y determinan lo que son la justicia y el bien común.

La tesis de Hinkelammert abarca a la sociedad en todas sus dimensiones, caracterizándola en función de las condiciones de posibilidad de la vida humana. Aparece, entonces, un criterio de discernimiento que se refiere a la sociedad entera. Este es un criterio que rige también sobre la economía, si se entiende economía como es usual hoy, es decir, como el ámbito del uso sostenible y sustentable de los recursos en un contexto de respeto por la vida y la dignidad humana. Estas condiciones de posibilidad de la vida, constituyen el circuito natural de la vida humana, esto es, que permiten el florecimiento o marchitamiento de los seres humanos, puesto que no hay vida posible sin que ésta esté incluida en dicho circuito. Por consiguiente, el deterioro de las fuentes originales de toda producción posible es la otra cara del detrimento de este circuito natural.

En esta medida, es necesario construir identidades ciudadanas que, desde las políticas públicas y la planeación económica, promuevan el desarrollo, la educación, la cultura y la paz; y que reivindiquen la sociedad en la cual puedan vivir todos los seres humanos y seres vivos del planeta, es decir, una sociedad justa en función del bien común. A este respecto, la economía y el derecho deben estar al servicio del bien común, deben garantizar tanto la verdad, justicia y reparación ante toda clase de violación de derechos, como también que la sociedad produzca riqueza y la distribuya equitativamente, conservando sus fuentes: la tierra y el ser humano. El ser humano, como ciudadano, es el único sujeto capaz de transformar el sistema, para que exista bienestar para todos. Por ende, es indispensable recuperar el derecho político de la intervención en los mercados, que en manos de unos pocos, han acabado con el bien común y el patrimonio público y privado con función social.

Así como lo recuerda Yamin, A. (2006), las anteriores afirmaciones nos muestran que el papel de los derechos es democratizar la economía. Sin embargo, esta democratización tiene su pilar principal en el derecho ciudadano de asegurar una política de la intervención en los mercados y, por consiguiente, en el poder de las grandes potencias. Para recuperar la ciudadanía y el equilibrio económico, si recordamos a John Mynard Keynes, es inminente recuperar este derecho fundamental a la intervención sistemática en los mercados. Igualmente, es necesario implantar la democracia en la identidad de los ciudadanos, con el fin de recuperar la libertad de opinión, desvirtuada en nombre de la libertad de prensa la cual ha permitido establecer el control, casi ilimitado, sobre los medios de comunicación por parte de las transnacionales. El derecho debe garantizar la libertad de prensa, para que posibilite la libertad de opinión de la ciudadanía. Algo similar tiene que ocurrir con las libertades de elecciones, huelga, cátedra, organización y expresión. Se debe recuperar la libertad en el sentido de que la ciudadanía sea capaz de elegir a sus representantes, siguiendo opiniones generadas en ambientes de garantía de la libertad de opinión.

En esta medida, la tarea de la economía frente a los derechos humanos, en Colombia y en todo el mundo, es lograr el bien común, esto es, promover acciones sociales y políticas que generen desarrollo 
y equidad, frente a las dificultades de la globalización. Lo que significa recuperar la democracia, recuperar las libertades y la capacidad del ciudadano y del Estado para controlar la economía y disponerla al servicio del florecimiento de la vida humana y de la protección del planeta.

La revista Finanzas y Política Económica, siendo coherente con el lema de la Facultad de Economía de la Universidad Católica de Colombia, el cual dice: "Comprometida con el desarrollo económico-social, incluyente y sostenible", es hoy un espacio de discusión que, desde la investigación y la academia, pretende aportar soluciones a las problemáticas sociales y de la naturaleza, las cuales generen un desarrollo con bienestar e igualdad. En esta medida, presentamos a nuestros lectores siete artículos, que son producto de estas preocupaciones de la sociedad contemporánea.

En primer lugar, Rosa María Armenta Vergara, William Orlando Prieto Bustos y Carlos Alberto Barreto Nieto, de la Universidad Católica de Colombia, analizan la relación entre las regalías directas y las coberturas mínimas alcanzadas por los municipios productores de petróleo entre 2007 y 2008 , mediante la metodología del análisis envolvente de datos, la cual se implementa en diferentes estudios que evalúan la eficiencia en la gestión gubernamental, pero que en Colombia no cuenta con evidencia de su utilización en la gestión de las transferencias por explotación de petróleo. Los resultados revelan una eficiencia técnica pura promedio del $24 \%$ para el 2007 y 19,6 \% para el 2008, en los cuatro modelos analizados. Al finalizar el artículo, se concluye que pocos municipios presentan un desempeño eficiente en cuanto a la gestión de las regalías.

En un segundo momento, José Ruiz Chico y Antonio Rafael Peña Sánchez, de la Universidad de Cádiz, España, analizan la competitividad de la industria agroalimentaria, en especial, del sector cárnico, de las regiones españolas, a partir de elementos que influyen en ésta, como son la productividad, los costes salariales y la seguridad alimentaria. De esta manera, se puede identificar la enorme potencialidad económica del sector agroalimentario español, y del subsector cárnico en particular. Aspectos como el tipo de carne o el nivel de internacionalización, identifican las regiones españolas que requieren esfuerzos en las políticas alimentarias, para evitar que su competitividad se perjudique.

El tercer artículo es una reflexión realizada por Joan Miguel Tejedor Estupiñán, en la cual se muestran algunas relaciones entre el modelo económico y los derechos humanos, por medio de una mirada a los antecedentes del modelo de economía política neoliberal en Colombia, los cuales permiten analizar, objetivamente, su impacto sobre el desarrollo y la trasformación de los derechos económicos, sociales y culturales de los colombianos en las últimas dos décadas. Por medio de un método de revisión de varias investigaciones, se describe que el modelo neoliberal no es sostenible, ni genera respeto por los derechos de los colombianos. Esta reflexión, se elaboró desde un método inductivo, apoyado en el análisis crítico de fuentes originales.

El cuarto estudio es desarrollado por Jorge Enrique Garcés Cano, Catedrático de la Universidad Konrad Lorenz (Bogotá), describe cómo el trabajo constituye una crítica al corazón de la teoría neoclásica - soporte ideológico de las argumentaciones neoliberales- cuya conexión con la actual enseñanza mundial de la economía es evidente, basada en supuestos del funcionamiento armónico del capitalismo elevados a la categoría de ciencia: equilibrio, manos invisibles, eficiencia en la producción, 
fuerzas naturales como leyes del mercado, tendencias inerciales a la ocupación plena y justa de todos los recursos productivos, eficacia maximizadora en todos los órdenes, etc. El autor rechaza la concepción de economía como "ciencia de la escasez", centrando el debate de la Economía Política en el estudio de las relaciones sociales de producción, distribución, acumulación y consumo, entre clases sociales con intereses en conflicto, manifiestas en todos los aspectos de la vida humana.

En quinto lugar, Raúl Cortés Landázury, de la Universidad del Cauca, muestra cómo en las sociedades democráticas, el sector público es un agente creado por los individuos para proveer colectivamente los bienes y servicios que el mercado es incapaz de suministrar de forma eficiente y equitativa. Lo cual se evidenció con la crisis económica que atravesaron las potencias occidentales a finales de los noventa, y aumentó las críticas a la economía pública por el exceso de proposiciones normativas ligadas al modelo de libre concurrencia. El autor muestra que este tipo de argumentaciones tiende a desdeñar los alcances del enfoque positivo frente a los desafueros de las aplicaciones político-administrativas. Por último, revisa el grado de avance de la economía del sector público frente a la problemática de la intervención social y la interpretación del rol del Gobierno en la actividad productiva, diferenciando sus elementos positivos de los juicios normativos.

En el sexto artículo, David Cano Ortiz, economista de la Universidad Nacional de Colombia, busca determinar si la regla fiscal puede tener algún impacto sobre la tasa de cambio, que logre mitigar los efectos de la enfermedad holandesa. El autor realiza un experimento contra-factual, simulando la implementación en Colombia, en los últimos treinta años, de una regla fiscal, como la aprobada por el Comité Técnico Interinstitucional. Lo anterior, a través de un modelo de tasa de cambio real de equilibrio y de un análisis de cointegración en un modelo VEC, concluye que la regla fiscal, lograría mitigar la apreciación, pero a la vez pueda incrementar la volatilidad cambiaria.

Finalmente, tenemos el artículo de reflexión de Sergio René Cortés Rincón, profesor de la Facultad de Economía de la Universidad Católica, el cual describe cómo el deber ser de las localidades de Bogotá se encuentra en entredicho por el marco legal que las regula y por unas figuras territoriales que no aportan al desarrollo de la ciudad. Explica también de qué manera los procesos políticos, financieros y administrativos de la capital no contribuyen a fomentar la eficiencia del gobierno distrital. Se presenta un análisis crítico de la realidad institucional de las localidades, evidenciando elementos que explican su decaimiento y la capacidad que tienen para dar solución a los problemas de su sector. Se considera la importancia de afianzar el control fiscal y se especifica el éxito que ha tenido en otros países la delegación de competencias en diferentes niveles de gobierno, como ejemplo para profundizar el debate que hoy tiene en el olvido, la descentralización de la ciudad.

Joan Miguel Tejedor Estupiñán

Editor 